VARIA 



\title{
ANÁLISIS CRÍTICO DE LOS RAZONAMIENTOS ANALÓGICOS DE JUDITH THOMSON
}

\author{
Jeannette Campos Salas
}

\begin{abstract}
RESUMEN
Anteriormente se han determinado, interpretado y analizado lógicamente los razonamientos por analogía de la filósofa norteamericana Judith Thomson (Revista de Filología y Lingüística XXXI (2): 249-270, 2005). En este artículo se pretende desarrollar una crítica a tales razonamientos. Este análisis crítico se hará tomando en cuenta todas las analogías, pero clasificadas en conjuntos. Esto debido fundamentalmente a que las analogías coinciden en puntos importantes, que van a ser considerados en esta segunda parte del trabajo. Solo la analogía del violinista será analizada y criticada por aparte, porque ha sido considerada la más fuerte de toda la argumentación.

Palabras clave: aborto, analogías, razonamientos, lógica, mente, cuerpo, feto, conciencia, derecho.
\end{abstract}

\begin{abstract}
Previously in this journal, the analogical reasoning of the North American philosopher Judith Thomson has been illustrated, interpreted, and logically analyzed (Revista de Filología y Lingüística XXXI (2): 249-270, 2005). Therefore, the purpose of this article is to develop a critical analysis of this reasoning. This analysis will take into account all the analogies and will classify them as they share important points that are going to be considered in the second part of the work. Only the analogy of the violinist will be treated separately because it has been considered the strongest in argumentation.
\end{abstract}

Key words: Abortion, Analogy, Reasoning, Logic, Mind, Body, Fetus, Conscience, Rights.

\section{Introducción}

Las premisas de los razonamientos por analogía de Judith Jarvis Thomson, cuya estructura lógica fue determinada y publicada (en esta revista) anteriormente, coinciden en puntos importantes, los cuales permiten una reflexión filosófica acerca de las afirmaciones que se expresan en dichos razonamientos.

Licda. Jeannette Campos Salas. Profesora de Filosofía de la Escuela de Estudios Generales de la Universidad de Costa Rica, San Pedro, San José, Costa Rica.

Correo electrónico: jeancampos2001@yahoo.com

Recepción: 16- 2- 2008

Aceptación: 14- 5- 2008 
Los puntos importantes en los que he considerado coinciden las premisas de estos razonamientos, en grupos determinados y que van a ser criticados aquí, son los siguientes:

a) El problema de la separación mente-cuerpo, en tanto que, en la mayoría de los casos se analoga o es comparado el cuerpo de la mujer con objetos materiales exteriores a ella, como una casa, un abrigo o una caja.

b) El problema de la conciencia y el feto, en tanto que en otros casos se presenta una evidente disparidad entre un sujeto con conciencia y un feto inconsciente; y

c) El problema del derecho a disponer del propio cuerpo, en tanto que este es proclamado por la autora durante casi toda la argumentación sin medir las consecuencias morales que puede implicar admitir ese derecho sin restricciones.

\subsection{El problema de la separación mente-cuerpo}

El primer grupo de analogías con que vamos a iniciar la discusión incluye aquellas que implican una separación entre la mente y el cuerpo. Este grupo de analogías está constituido por la analogía de la casa diminuta, de la dueña de la casa, del abrigo, de la caja de bombones, del ladrón y de las mallas defectuosas.

En estos casos, es claro que el cuerpo de la madre o parte de ese cuerpo que alberga al niño, es analogado a una casa, a un abrigo o a una caja. Todos estos son objetos de los cuales se es dueño y por lo cual se puede disponer de ellos. Al analogar el cuerpo a una casa, abrigo o caja, se busca producir el convencimiento de que, por la naturaleza de la casa, del abrigo o de la caja de bombones, la mujer tendría derecho a disponer de su cuerpo como crea o decida conveniente. Con base en estas semejanzas el cuerpo de la mujer es considerado como un bien material que se ha adquirido y que se posee con los derechos de rigor.

Es extraño que Thomson caiga en la comparación del cuerpo de la mujer con un objeto. La cultura patriarcal ha visto el cuerpo de la mujer de este modo. La mujer ha sido cosificada por siglos y su cuerpo ha sido visto como un objeto sexual, procreador, del que siempre han dispuesto otros. Siendo su argumento una defensa del aborto ubicado dentro de la postura feminista, no cabría o no sería aceptable dicha comparación. Thomson parece considerar el cuerpo de la mujer como un objeto, según lo ha considerado el patriarcado, pero deja claro dentro de la argumentación y en defensa al derecho a disponer del cuerpo, que ese es un cuerpo (objeto) del que solo ella puede disponer. Ahora bien, aunque el cuerpo de la mujer sea visto como un objeto, la crítica al uso de estos elementos como recurso para la argumentación va más allá y plantea que, al analogar el cuerpo a una casa y el sujeto moral a su dueño (a), esto supondría una separación ontológica entre mente y cuerpo. Esta observación hace que las premisas analógicas establecidas en estos razonamientos de Thomson no sean necesarias o evidentes y por ende, debilitan su argumento.

En las premisas de estos razonamientos el agente moral es representado por la dueña de la casa, el dueño del abrigo o el dueño de la caja de bombones. Desde el punto de vista señalado, el agente moral dejaría de actuar en unión con su cuerpo o podría hacerlo separado de este.

En la analogía de la dueña de la casa, analogía que se desprende de la de la casa diminuta, hay que considerar que la dueña de la casa podría salir de su casa y separarse de esta. En caso de que la alquilara, ni siquiera podría habitarla. Además la dueña de la casa podría 
subsistir fuera de la casa si esta se destruye, mientras que no entendemos cómo subsistiría una persona o sujeto moral fuera de su cuerpo.

Lo mismo ocurre en la analogía del abrigo. El dueño de un abrigo puede prescindir de ese abrigo si el frío no es exagerado. Un dueño de un abrigo podría permanecer o existir aún sin su abrigo si este se le ha perdido, o si este le fuera arrebatado por otra persona, mientras que una persona no podría hacerlo separada de su cuerpo. No podría alguien perder ese, su cuerpo, o que este le fuera arrebatado, sin perder sus funciones vitales. La persona estaría incompleta, no sería una persona en su totalidad.

Igual observación señalo en las dos versiones de la analogía de la caja de bombones. Al ser comparado el cuerpo de la mujer con una caja de bombones pensamos que el dueño o dueña de una caja de bombones podría totalmente prescindir de esa caja de bombones. Por más que tenga o no que compartirse, una caja de bombones es ontológicamente distinta y separada de su dueño, y una vez terminados los tentadores y deliciosos chocolates, el dueño de la caja podría, si quiere, tirarla en cualquier lugar y olvidarse de ella, mientras que ninguna persona podría subsistir separada de tal manera de su propio cuerpo.

El punto aquí no es que el problema señalado refute el argumento, sino, más bien, que lo debilita, pues una parte de las premisas que lo componen suponen un dualismo al cual se opondría, por ejemplo, el punto de vista materialista. El materialismo ha considerado la conciencia como parte del cuerpo y no separada de este. Habría que ser dualista para aceptar que hay una separación o distinción de tal tipo entre cuerpo y mente o entre cuerpo y conciencia. No solo el materialismo considera la unidad de conciencia y cuerpo, y lo importante no es que se contradiga el materialismo, sino que unas premisas no fundadas debilitan el argumento.

Se ha de tomar en cuenta en esta parte de nuestra crítica, que la radical separación entre cuerpo y mente o cuerpo y pensamiento se remonta a diversos pensadores desde tiempos antiguos. El pensamiento platónico influyó sobre el cristianismo en relación con este tema. A partir de la argumentación de Platón acerca de la inmortalidad de las almas, el cuerpo es visto como una cárcel de esta. Posteriormente, Descartes separa claramente la res cogitans de la res extensa, es decir el ser pensante, del ser material.

Desde el punto de vista del espiritualismo cristiano o del dualismo cartesiano sería aceptable tal separación, pero la aceptación de esta dualidad ha sido ya negada por muchos otros pensadores y desde supuestos muy distintos.

En la Fenomenología de la percepción (1945) el existencialista y fenomenólogo francés Merleau-Ponty defiende la idea de la conexión indisoluble entre el sujeto y el objeto. Sostener que los datos inmediatos de la percepción contribuyen a la realidad verdadera significa situarse en un idealismo subjetivo.

\footnotetext{
La peculiar unidad del cuerpo, distinta de la unidad del cuerpo como objeto científico, no conduce a la "reducción del cuerpo" ni en el sentido del sensacionismo ni en el del idealismo. En verdad parece que la fenomenología del cuerpo en el sentido de Merleau-Ponty da como resultado el cierre del ciclo abierto por Descartes con la separación entre cuerpo y alma y soluciona todos los debates habidos durante la época moderna acerca de esta cuestión (debates en os cuales participaron tanto los "espiritualistas" como los "materialistas" por haber todos ellos planteado el problema en los mismos términos). Así, 'a la unidad del alma y del cuerpo -dice el mencionado autor- no queda sellada por medio de un derecho arbitrario entre dos términos exteriores, uno objeto y otro sujeto. Se realiza a cada instante en el movimiento de la existencia (Merleau- Ponty 1945: 389).
}

La pregunta ¿qué es el cuerpo? se transforma en ¿cómo se vive la corporeidad y cuáles son las características fundamentales de esta vida? La respuesta se coloca así en el campo total del existir humano concreto, en el cuerpo-vida, cuya existencia consiste en el diálogo del ser humano 
con el mundo. Esta nueva perspectiva inicia la des-objetivación del cuerpo y su consiguiente fenomenalización. Hay una verdadera dialéctica en esta concepción del ser humano.

Merleau- Ponty confirma la imposibilidad de establecer una dualidad entre "mi cuerpo" y "mi subjetividad", dualidad que desaparece tan pronto como se concibe la existencia como un "ser-en-el-mundo".

El tema ha sido tratado también por Jean Paul Sartre, al definir y diferenciar el en-sí del para-sí. Este punto de partida plantea, dentro de una teoría general del ser, la diferenciación de los modos del ser: el de la conciencia y el de la cosa. La cosa es "en-sín", la conciencia es "para-sí". Y sin embargo, hay una unidad:

\footnotetext{
El para-sí es el en-sí que se pierde como en-sí para fundamentarse como conciencia. El en-sí no puede fundamentar nada, si se fundamenta a sí mismo lo hace dándose la modificación del para-sí. Es fundamento de sí mismo en cuanto deja de ser en-sí (Sartre 1981: 201).
}

Para Sartre el para-sí es el en-sí que se pierde como tal para fundamentarse como conciencia. El problema del ser no puede ser entonces considerado como un falso problema dentro del pensamiento sartriano. La ontología será la descripción del fenómeno del ser tal y como se manifiesta a nivel de lo cotidiano. El ser se nos revela por algún medio de acceso inmediato, como el hastío o la náusea y esta evidencia completa del ser en toda vida, no es más que la presencia en la conciencia de su propia materialidad. Es el disfrute o no disfrute que le viene a la conciencia de su cuerpo.

Hay pues, una parte significativa de la antropología filosófica del siglo XX que apoyaría esta crítica que hacemos a las premisas analógicas de Thomson, que suponen una separación entre mente-cuerpo. Gran parte de esta antropología insiste sobre una visión integralista del ser humano, en el sentido de que no es un espíritu o una mente que posee un cuerpo, sino una integralidad indivisible.

Cuando nos vemos tentados a pensar en el cuerpo como si fuera un instrumento del que la conciencia se sirve, este se ve reducido a ser una cosa y el yo a su dueño, como lo hace Thomson. Para el filósofo y escritor Gabriel Marcel, el problema radicaría en la base del planteamiento, ya que:"“yo no puedo ponerme frente al cuerpo y preguntarme qué es con respecto a mí. Mi cuerpo deja de ser mío al ser pensado así” (Marcel 1956: 312).

Desde esta perspectiva Marcel, al igual que Merleau- Ponty, critica al materialismo y al idealismo en su forma de ver la corporalidad. Para Marcel, uno no puede limitarse a servirse de su cuerpo porque: "hay un sentido en el que yo soy mi cuerpo" (Merleau-Ponty 1945: 238).

A diferencia de cualquier posesión en la que se afirme la independencia o separación de lo poseído, como lo hacen estas premisas de los razonamientos de Thomson, con el cuerpo no hay tal independencia o separación. No es entonces mi cuerpo el que utiliza o el que percibe, soy yo quien lo hace, porque "yo soy mi cuerpo".

Por su parte, la reflexión ontológica del filósofo italiano Michele Federico Sciacca reconoce también esta unidad indisoluble entre mi yo y mi cuerpo. Para Sciacca, la integralidad del ser humano se encuentra y se descubre en situaciones concretas donde acontece la existencia. Es decir, no solo en el espíritu o la mente si lo interpretamos separadamente, sino en la compleja y dinámica unidad del existir. Según Sciacca:

soy yo mismo con mis ideas y mis sentimientos, con mi inteligencia y mis pasiones mientras actualizo la singularidad concreta de mi persona que vive en el mundo (Sciacca 1962: 8).

Se trata de una antropología en la que:

el yo es una unidad, viviente y concreta, una singular esencia espiritual encarnada (Sciacca 1958: 14- 15). 
El fundamento de la unidad ontológica entre la mente y el cuerpo, también puede verse desde otras perspectivas. En los estudios y reflexiones de Paul y Patricia Churchland, por ejemplo, el problema es tratado desde un materialismo neuro-reduccionista. La mente es considerada como parte del sistema nervioso.

Podemos considerar, entonces, que el sujeto pensante con cuerpo y conciencia o aprehensión sobre el mundo y la interpretación que hace de este, establece una relación interdependiente entre ambas partes. Desde este punto de vista, el cuerpo humano o el cuerpo de una mujer, no puede ser igual a una casa concreta e inmóvil, cuyas paredes pueden o no resguardar cosas dentro de sí, incluidas personas, sin ninguna responsabilidad real o concientización de un hecho particularmente complejo. Lo mismo se extendería al uso de un abrigo o de una caja de bombones.

De manera que, en la analogía de la casa diminuta podemos hacer notar que una mujer embarazada cuya vida se vea amenazada por un feto en crecimiento no se encuentra en condiciones tan semejantes a las que se encontraría una persona que se encuentra en una casa diminuta con un niño que crece muy deprisa. El útero, como órgano de la gestación en la mujer, y que ha sido comparado ya en la interpretación de la analogía con la casa "realmente diminuta", es parte fundamental de la anatomía femenina, de su "naturaleza biológica" y de su desenvolverse en el mundo consciente de esa realidad, y no un "objeto" concreto aparte de ella o dentro del cual se encuentra ella también encerrada.

Vamos a señalar también, que, si no hay dualismo, las características que presenta una casa con dueña, no son las mismas que se presentan en una mujer embarazada en relación con su cuerpo a la hora de decidir si lleva a término su embarazo. La parte material es la casa que correspondería al cuerpo, y el hecho de que ella sea su dueña no la une a esta como estaría realmente unida una mujer a su cuerpo.

Por otra parte, la aceptación de estas premisas que admiten tales semejanzas establecen dentro de los razonamientos de J. Thomson la propiedad que hace concluir que una mujer que quede embarazada y cuya vida corra peligro de muerte, tiene derecho a atacar al niño, o que una mujer embarazada que es dueña de una casa tiene derecho a echar a su inquilino ya analogado con el feto; o que una mujer que quede embarazada sin haberlo deseado tiene derecho a echar al intruso que ha entrado a su casa sin su consentimiento. Sin embargo, estas premisas resultan también cuestionables.

Es cierto que si poseo una casa adquiero ciertos derechos sobre esa casa y sobre el inquilino que la habite en caso de que la alquilara. Pero también es cierto que no siempre un dueño o dueña de una casa puede echar a su inquilino cuando se le ocurra. En muchos países las leyes benefician y protegen al inquilino y se puede hacer muy difícil hacerlo desalojar. Es decir, que el derecho de poseer una casa no autoriza siempre a su dueño a disponer de ella cuando quiera y como mejor le parezca.

La validez o aceptación de esas segundas premisas, que autorizan cierto tipo de acción por solo ser uno dueño de algo, nos hace pensar también en aquellos países donde la forma básica de propiedad es la social y no la privada. Aunque actualmente los países con régimen comunista o socialista sean muy pocos, la propiedad analogada admitida a partir de estos razonamientos interpretados sería cuestionable o podría poner en desventaja a todas aquellas mujeres embarazadas que vivan y se desarrollen dentro de esa forma de organización política o gubernamental. ¿Podrían estas mujeres acreditarse o lograr adquirir ese derecho a disponer de su cuerpo, de lo suyo, del mismo modo que las mujeres de los países capitalistas? 
Probablemente Judith Jarvis Thomson contestaría a toda esta crítica diciendo que para hacer entender la "injusta prioridad de uno sobre su propio cuerpo" y "el derecho a disponer del cuerpo" se ha hecho necesario recurrir al uso de estos objetos, como elementos ilustrativos acerca de la posibilidad que tiene un propietario de disponer de lo que le pertenece y en relación con el derecho que se puede obtener de todo esto; para eso, su argumentación ha sido mediatizada por analogías y estas lo permiten. Además, alguien que es dueño de algo y pueda disponer de eso sería "consciente" de esa posesión, es decir, que a una mujer, así como a la dueña de una casa, le interesaría o le incumbe personalmente que haya o no un inquilino o un intruso dentro de ella. Sin embargo, al presentar en estas analogías a la mujer en relación con su cuerpo como una persona en relación con su casa o en relación con cualquier otro objeto material separado de ella esencial y ontológicamente, no se está contemplando la condición fundamental de la unión indisoluble que experimenta una mujer consciente en relación con su cuerpo principalmente en caso de un embarazo o de un aborto. Esta observación es importante, quizá tenga más repercusiones psicológicas y emocionales que formales o jurídicas, pero resulta necesario tomarla en cuenta, pues determina características moralmente relevantes en un tipo de acción como el aborto.

La mujer embarazada, como agente o sujeto moral, es parte de su propio cuerpo y no puede apartarse de este como objeto exterior a ella. Además, el feto surge como producto de ese mismo cuerpo.

La consideración del cuerpo de la mujer o de parte de ese cuerpo como si fuera una casa, un abrigo o una caja de bombones lo hace ver, de algún modo, separado de su capacidad de pensar, de discernir y de decidir en relación con algo que la delimita y la conforma. Por más que sea una mujer la dueña de todos estos objetos, su cuerpo parece ser presentado como una cosa separada de su pensamiento, lo cual nos conduce a la importante consideración de la conciencia como percatación o reconocimiento de algo, ya sea de algo extraño o exterior, como un objeto, una cualidad, una situación, etc.; ya sea de algo propio e interior, como las modificaciones experimentadas por el propio yo.

La mujer, y sobre todo una mujer embarazada como agente moral en el caso de un aborto, se encuentra en íntima relación con su cuerpo, o es y actúa como alguien que es al mismo tiempo conciencia, sujeto de decisión y cuerpo. Como sujeto moral constituye una autoridad para estimar la moralidad de un acto, y, debido a la facultad de hacer algo, que le otorga la voluntad a través del pensamiento y la conciencia, y en íntima relación con el cuerpo, una mujer actúa bajo el conocimiento de lo que hace y lo juzga correcto o incorrecto. Al suponer este grupo de analogías la separación entre la mente y el cuerpo, suponen un agente moral escindido en un caso donde tal división no se daría ni se justificaría.

La mujer embarazada, como agente moral en todas estas analogías, se enfrenta a una situación o decisión muy distinta a las expuestas por la autora, debido a la necesidad de tener que actuar sobre algo que, aunque sea suyo y le pertenezca, le es intrínsecamente inseparable. La semejanza de relación que se establece entre un cuerpo humano o el cuerpo de la mujer y un puro objeto material exterior a ella, un tanto separado de su verdadera condición para desenvolverse física, consciente y moralmente como ser- en- el- mundo en determinada circunstancia, es lo que criticamos aquí. Si el hecho de poder disponer de mi propio cuerpo supone una conciencia de ese cuerpo como mío, pero visto desde afuera, este problema de la separación o unión entre mente y cuerpo señalado, limitaría esa posibilidad. 
Es por estas razones, que hemos considerado que las premisas analógicas de estos razonamientos que asumen la comparación de exteriores objetos concretos con el cuerpo de la mujer dentro de la argumentación, no son necesarias ni filosóficamente evidentes.

\section{El problema de la conciencia y el feto}

Vamos a considerar en este apartado otro grupo de analogías dentro de la argumentación de Thomson que analogan el feto a un individuo con conciencia. Esto se presenta en las analogías de Henry Fonda, de la casa diminuta, de la dueña de la casa, del abrigo, de la caja de bombones y del ladrón. Dentro de este grupo de razonamientos se manifiesta la analogía fundamentada en la comparación de dos sujetos conscientes en diversas situaciones o eventualidades (como la dueña de una casa y un ladrón), con una mujer embarazada y un feto, haciendo caso omiso de la notable diferencia que se presenta entre un sujeto con conciencia y un feto inconsciente.

Thomson afirma que una mujer embarazada en relación con su cuerpo y con el feto es como una "dueña de una casa" en relación con su "inquilino", en relación con un "ladrón" o en relación con un intruso. También afirma que una mujer embarazada en relación con el feto es como una persona famosa en relación con otra persona "enferma de muerte", o una persona "dueña de un abrigo" en relación con otra persona que también necesita ese mismo abrigo; o que una mujer embarazada es como un "hermano mayor" dueño de una caja de bombones en relación con su "hermano menor", quien seguramente también querrá bombones.

No podemos dejar de señalar el hecho de que un inquilino, un intruso, un ladrón, una persona "enferma de muerte" o un niño son personas con conciencia e intenciones propias. $\mathrm{Y}$ al aceptar que entre ambas partes involucradas en las analogías una tiene conciencia y la otra no, estamos aceptando que hay una importante disparidad que se coloca, sin problemática alguna, dentro del ámbito de las relaciones morales. La relación que se establece entre los sujetos involucrados en estos razonamientos es una relación entre dos sujetos morales con las mismas posibilidades de discernir entre un acto y otro. Mientras que en el caso de un embarazo y la posibilidad de abortar, la relación que se establece entre un feto inconsciente y una mujer embarazada como sujeto consciente, capaz de discernir y de responsabilidad moral, se presenta una evidente desemejanza entre los términos del tema y los términos del foro analogados.

Las analogías de Thomson colocan a un sujeto con conciencia y por tanto, con conciencia moral, frente a otro sujeto que actuaría también moralmente bajo estas mismas condiciones y al mismo nivel de conciencia. Y en el caso de una mujer embarazada y un feto esto no se daría. La importante diferencia que se establece en semejante interacción humana es que el sujeto moral sabe que sabe y puede emitir un juicio sobre la moralidad de su propia acción. El agente moral es juez de sí mismo y de sus actos y un ser inconsciente no puede ser juez ni parte en ninguna situación.

Quizá la autora insiste en colocar a un mismo nivel ambas partes involucradas en las analogías porque el feto ha sido considerado "persona" para la argumentación, pero tales afirmaciones dejan de lado la importante disparidad que se establece entre un sujeto con conciencia y otro sin esta. Si tomamos en cuenta las evidentes y trascendentes diferencias que manifiesta dicha disparidad, las premisas de estos razonamientos no se sostienen. Si entendemos la relación de semejanza que pretenden establecer estas premisas analógicas y las elementales condiciones que limitan dichas semejanzas, los razonamientos pierden fuerza y validez. 
Así, en la primera premisa de la analogía de Henry Fonda se afirma que un feto que necesita de una parte del cuerpo de la mujer para vivir, es como una persona "enferma de muerte" que necesita de una parte del cuerpo de otra para salvar su vida. Aunque esta analogía nos haga pensar que una persona no tendría por qué disponer siempre del cuerpo y la presencia de otra para sobrevivir, también nos lleva a observar que una persona adulta, "enferma de muerte", que requiere de una parte del cuerpo de otra para mantenerse con vida, no es igual o tan semejante a un feto inconsciente, que no ha iniciado aún una vida independiente y que requiere de una parte del cuerpo de una mujer para vivir. Es claro que el feto en circunstancias de inicio de un embarazo no tiene un cuerpo formado y cuando ya lo tiene, no tendría el manejo, ni las mismas condiciones de vida o de conciencia que tiene un adulto a quien se le ha comunicado que está "enfermo de muerte".

La misma objeción planteamos a las analogías del ladrón y de la dueña de la casa, cuyas primeras premisas analogan o comparan al feto, con un intruso, y a una mujer que alberga en su cuerpo un feto, con una dueña de una casa.

Lo que una mujer embarazada es en relación con un feto inconsciente, no es lo mismo que lo que es una dueña de una casa en relación con un ladrón, un intruso o un inquilino conscientes de una situación y de su propia intencionalidad frente a esta.

La clara distinción entre los estados de conciencia de ambas partes involucradas en el caso de un aborto y los casos que presenta Thomson en sus analogías haciendo pensar que no existe tal distinción, nos lleva a señalar otra gran debilidad dentro de su argumento.

En la interpretación que hicimos de la analogía del ladrón cambiamos justificadamente el término "ladrón" por el de "intruso consciente", porque lo importante para el caso es que se trate de una persona que se introduce conscientemente, pero no ha sido invitada a entrar o a quedarse en la casa. El término "ladrón" indicaría que un sujeto se introduce al lugar a robar algo, y como es comparado con el feto en la analogía de Thomson, podríamos entonces pensar que este se introduce en la "casa" de la mujer a robar energía de su cuerpo o espacio y tiempo para la dueña del lugar. Sin embargo, es claro que el feto no se introduce en el cuerpo de la mujer de manera "consciente" o con la intención de robar, como lo hace un ladrón en una casa de la que no es dueño. Como se sabe, la presencia del feto en el útero materno no se da de esta manera, ni tampoco se da siempre de improviso, a escondidas, o violentando las reglas de entrada al lugar donde tendría que permanecer para sobrevivir. En este caso del "ladrón", que hemos llamado también "intruso consciente", más que en cualquier otro de los casos, el sujeto usurpador no puede ser visto sin su conciencia. El feto, que es inconsciente, no tendría la facultad que juzga la moralidad de sus acciones e intenciones, como sí la tendría la mujer y como sí la tendría el ladrón o el intruso consciente, o la persona "enferma de muerte"; o el inquilino que alquila o comparte una casa. Las premisas analógicas de este grupo de razonamientos de Thomson olvidan esto.

Judith Thomson podría objetar que si observamos cuidadosamente sus analogías podríamos detectar alguna diferencia entre las personas relacionadas, y que estas personas no han sido colocadas exactamente en el mismo nivel. En este grupo de analogías se presenta alguna mínima pero quizá importante diferencia entre las partes involucradas, pues entre ambos sujetos relacionados y analogados en los casos expuestos se establece también, de alguna manera, una caracterización "inferior" del sujeto que representa al feto, como lo es la persona "enferma de muerte" en la analogía de Henry Fonda. Esta persona parece estar limitada físicamente por la enfermedad que padece, pero no parece estar limitada mentalmente, ya que 
se le ha ocurrido la posibilidad de que traigan a Henry Fonda a posar su "mano fría" sobre su "frente febril" para salvarse. O el "niño que crece deprisa", que no se manifiesta incompetente físicamente en la analogía de la casa diminuta, pero es un "niño" y no una persona "mayor". O bien el "ladrón", un "intruso" o el "inquilino" en las otras analogías, pues estas personas se ven afectadas o disminuidas por un condicionamiento social establecido, dentro del cual la dueña o dueño de una casa ocupa siempre un lugar de autoridad o superioridad frente a las personas que la invadan, alquilen o habiten. Sin embargo, habría que seguir señalando a la autora que no llegan a ser personas "inconscientes" como lo es un feto.

Y si el intruso consciente ¿se introdujera a la casa por razones ajenas a su voluntad? Podría ser un perseguido político, que en lugar de entrar a su casa a robar, entraría a buscar refugio debido a una posible persecución justa o injusta. Podría ser también una mujer herida de muerte o perseguida para ser violada, a quien usted no conoce pero que llegó hasta su casa solicitando ayuda y ¿tendría usted derecho a echarlas? ¿Tendría toda persona el mismo reparo moral que se pretende justificar dentro de este argumento en defensa del aborto para no dejarlas permanecer allí y no asistirlas?

Es decir, en todas estas analogías habría que observar cuidadosamente si las mismas razones que nos hacen rechazar el derecho a la permanencia del "intruso consciente", del "inquilino" y de la persona "enferma de muerte", están presentes en el caso o circunstancias peculiares que rodean a un feto, y si esas son todas las razones relevantes para la cuestión. Si asumimos que el feto es una persona y lo colocamos al mismo nivel que la otra parte involucrada en las analogías expuestas y no aceptamos como importantes las diferencias y consecuencias morales aquí señaladas, podríamos estar de acuerdo con la argumentación hecha por la autora, pero tendríamos que aceptar como irrelevantes los elementos establecidos y analizados en tales semejanzas de relación y como irrelevantes también las críticas lógicofilosóficas aquí realizadas.

Es por todas estas objeciones que las analogías de Thomson, resultan cuestionables no solo lógicamente sino también éticamente, pues además de que muchas de las premisas analógicas propuestas al lector no son necesarias o evidentes, otras premisas no se sostienen y tampoco contemplan tantas otras posibles eventualidades o sucesos con repercusiones morales, que implican un cambio de dirección en el asunto propuesto.

Dentro de los casos analogados han entrado en juego categorías antropológicas y acciones que van más allá de una disputa por el derecho a disponer del cuerpo. El problema del cuerpo y la conciencia, que distinguen al agente moral por un lado, y el derecho a disponer y poder tomar decisiones en determinados casos que implican un juicio moral, por otro, parecen delimitar y permiten criticar de este modo el argumento planteado por Judith Thomson, a pesar de la aceptación de la premisa de que el feto es una persona.

\section{El problema del derecho a disponer del cuerpo}

El derecho a disponer del propio cuerpo defendido por la autora como argumento a favor del aborto es muy importante, si no fundamental dentro de toda la argumentación. Sus razonamientos en defensa del aborto se plantean principalmente sustentados en el derecho de la madre a disponer de su cuerpo frente al derecho a la vida del feto. De esta manera, el derecho de toda persona a la vida entra en conflicto con el derecho a disponer del cuerpo que tendría la mujer. 
Como el derecho a la vida es común a todas las personas y de lo que se trata es de enfrentarlo y medirlo con el derecho a disponer del cuerpo ¿tendríamos que admitir este último derecho también para todas las personas?

Habría pues que aclarar con Thomson qué garantiza este derecho a disponer del cuerpo, a qué clase de personas, si es afectado por prohibiciones o permisos de terceros y sobre qué tipo concreto de acciones.

Admitir que toda persona tiene derecho a disponer de su cuerpo es admitir este derecho no solo en caso de que se quiera practicar un aborto, sino en todo caso en el que alguna persona decida disponer de su propio cuerpo. ¿Qué podría significar esto? La afirmación de este derecho parece aceptable en algunos casos. Como por ejemplo, cuando una persona es víctima de una gangrena en su pierna o brazo derecho, habría que aceptar que automutile esa parte de su cuerpo o que otra persona lo haga por ella para evitar posibles consecuencias que afectarían desdichadamente su salud, todo su cuerpo, o atentarían contra su vida.

Pero ¿si una persona decidiera automutilarse cualquier parte de su cuerpo por cualquier otra razón, como Van Gogh?

\footnotetext{
Después de parar la hemorragia a duras penas, Van Gogh envolvió el pedazo de oreja cortada en un pañuelo y se fue con él al burdel de la ciudad donde se lo entregó a una prostituta. Como si nada hubiese ocurrido, regresó entonces a casa y se acostó (Walter. 1993: 58).
}

Allí durmiendo lo encuentra la policía e inmediatamente ingresa en el hospital municipal.

El caso de Van Gogh ilustra de buena manera la posible aceptación del derecho a la auto-mutilación por admitir el derecho a disponer del cuerpo. Este hecho causó asombro, conmiseración, preocupación y probablemente conmovió a todos los vecinos del pintor y a la prostituta merecedora de tal obsequio. La policía fue informada del asunto puesto que allanó el estudio del artista y lo trasladó al hospital. Su acción no provocó que lo encarcelaran, pero causó reacciones en las demás personas que lo rodeaban o que lo conocían y esas reacciones se podrían enmarcar dentro del ámbito de preocupaciones de la moral. La grotesca, brutal o irracional actuación del gran pintor chocó con las habituales costumbres de los ciudadanos que lo rodeaban.

Si consideramos, pues, este derecho que propone Thomson y lo admitimos sin restricciones, tendríamos que aceptar que le está moralmente permitido a una persona automutilarse o inflingirse daños que destruyan su salud física y mental, tales como el abuso del alcohol o el licor, del tabaco, o de cualquier otro tipo de droga con efectos estimulantes, deprimentes o narcóticos. Inclusive, habiendo llegado a este punto, hemos de plantear la posibilidad de que una persona como dueña y señora de su cuerpo, quiera poner fin a su propia existencia. ¿Tendríamos entonces derecho al suicidio? ¿Tendríamos derecho a poner fin de cualquier modo a nuestra existencia por las razones o sinrazones que consideremos válidas y oportunas?

Para el cristianismo el suicidio es moralmente inaceptable. Sin embargo, cuando Lucio Anneo Séneca se suicidó abriéndose las venas lo hizo frente a sus amigos. A pesar de que durante el desarrollo de ese período estoico en territorio romano, se elaboraron en lo fundamental las ideas morales y religiosas que influyeron posteriormente en el cristianismo. Los estoicos enseñaron que no debemos quejarnos de la vida, pues siempre estaba abierta esa puerta. Aún aceptando la máxima ética proclamada por esta corriente filosófica que consistía en "vivir conforme a la naturaleza", el suicidio era una opción éticamente aceptable.

Pensar en la posibilidad del suicidio, como consecuencia de la admisión del derecho a disponer del cuerpo, nos lleva también a preguntar si toda persona contaría realmente con el 
discernimiento necesario y con el deber responsable de conservar la integridad de su cuerpo. El caso del suicidio colectivo en La Guyana suramericana por fanatismos religiosos, causó conmoción en el mundo y los comentarios posteriores a este hecho, en su mayoría, emitían juicios negativos o de desaprobación. Lo mismo el suicidio de un grupo llamado "seguidores de extraterrestres" en Norteamérica, quienes siguiendo las instrucciones de un líder con evidente desequilibrio mental, creyeron firmemente que en un momento preciso e indicado debían morir para ser llevados a otros mundos.

La aceptación de este derecho a disponer del cuerpo nos conduce a todas estas delicadas objeciones morales y nos lleva a considerar cuidadosamente la propuesta de Thomson.

Podríamos reformular, siguiendo la argumentación y los razonamientos de la autora, que en caso de un embarazo no deseado la mujer (y no toda persona) tiene derecho a disponer de su cuerpo. En ningún momento, dentro de la argumentación, se plantea en estos términos la admisión de este derecho. Sin embargo, aún si lo replanteáramos de este modo, su aceptación estaría siempre susceptible a caer en modificaciones debido a la gran diversidad de perspectivas éticas, que suscitan diferentes posturas, diversas críticas o reproches morales y legales relativos al uso del cuerpo. Hay restricciones morales a la admisión del derecho a disponer del cuerpo, y el aborto podría ser una restricción a ese derecho. Este podría ser visto como una auto-mutilación y habría quienes lo rechazarían simplemente por eso. Los derechos se limitan también dependiendo del horizonte de donde se les mire. La aceptación del suicidio en Occidente por ejemplo, no es igual a la aceptación de este mismo acto en Oriente. Los orientales le han otorgado históricamente un carácter distinto al suicidio, el cual tiene que ver con la dignidad y el honor de las personas.

El análisis expuesto hasta aquí, acerca de la problemática que presenta la proclamación y admisión de este derecho a disponer del cuerpo, nos lleva a plantearle a la autora la posibilidad de admitir que, en muchos casos, hay deberes para con nosotros mismos y para con los demás, que limitan los derechos por sí mismos. Existe una dimensión ética en la autoafirmación del yo, en la afirmación de los propios derechos y en el autofortalecimiento. Dentro de esta dimensión Judith Jarvis Thomson se plantea bien. Pero hay también una dimensión ética en la solidaridad, en la posibilidad de prestar ayuda a los otros y en la consideración y el respeto a los demás.

\section{La analogía del violinista}

Se ha dejado aparte el análisis de esta analogía porque ha sido considerada la más fuerte de toda la argumentación. Este razonamiento, a diferencia de los anteriores, no asume que el representante del feto sea una persona consciente. Al contrario, el violinista, que representa al feto en esta analogía, es calificado por la autora como "un famoso violinista inconsciente". Este detalle indispensable y de mayor peso dentro del razonamiento hace que la analogía tenga que ser vista, analizada o criticada desde otra perspectiva. Vamos a utilizar algunos elementos a los que acude Thomson en la construcción de sus analogías para establecer semejanzas con el embarazo y, del mismo modo que ella lo hace, solicitamos que se nos permita decir lo siguiente:

Supongamos que usted es la dueña de una casa en el desierto y que un grupo de delincuentes ha dejado en su casa a un rehén inconsciente que habían tomado como tal para cumplir con los propósitos de una huida. Han dejado a esa persona inconsciente en su casa en el desierto para poder ejecutar otros planes relacionados con el narcotráfico. Usted descubre a la persona dentro 
de la casa. Esa persona se encuentra amarrada a una de las columnas de "su casa" y usted se entera por las noticias del por qué de su presencia allí. ¿Podría "desamarrarla" y echarla de su casa del mismo modo que echaría a un ladrón o a cualquier otro intruso? O ¿del mismo modo que se desamarraría del violinista? Si lo hiciera, las posibilidades de que sobreviva esa persona son muy pocas, pues se encuentra en un desierto y está inconsciente. ¿Podría usted arrojar a esa persona afuera sólo porque apareció sin su consentimiento en la casa? Puede que corra usted el riesgo de ver amenazada su propia vida si el exrehén se quedara allí y los maleantes volvieran. En este caso usted no esperaba que esa persona apareciera en su casa, pero el ex- rehén tampoco pidió que lo raptaran y lo dejaran allí. ¿Podría usted entonces simplemente echarlo fuera sin esperar siquiera que esa persona vuelva en sí o sin buscar asistencia de otras personas para ayudarlo o que le ayuden a usted?

Siguiendo la argumentación de la autora y habiendo comprendido su punto de vista y sus razonamientos, habría que contestar que sí tendría usted derecho a echarlo, que podría usted aceptar que permanezca allí por un tiempo mientras se recupera y pueda salir como un hombre libre, pero que no está usted obligada a hacerlo. Que si usted acepta que el ex-rehén se quede y lo ayuda, cumpliría con un acto de generosidad y que sería muy amable de su parte si lo hiciera, pero no tendría por qué acceder a mantenerlo dentro de su casa para que sobreviva. Probablemente si usted echa a esa persona fuera no estaría cometiendo un "asesinato directo” pero ¿no se recriminaría a usted misma moralmente o prestaría atención a la recriminación moral que le harían otras personas relacionadas con el rehén por haber decidido realizar tal acción?

Aunque podamos entender la diferencia que se da entre el cumplimiento de un deber y la obtención de un derecho que nos propone Thomson en sus analogías para justificar la permisibilidad del aborto, tenemos que aceptar que en muchísimos casos en los que se relacionan dos personas, el hecho de que una de las dos haya obtenido un derecho que respalde su actuación, no justifica que se pueda dejar de cumplir con deberes para con los demás.

La semejanza de relación que se establece en la analogía de las mallas defectuosas, provoca por un momento la misma inquietud que nos movió a analizar la analogía del violinista más cuidadosamente, ya que en este otro razonamiento el feto es analogado con una "plantapersona" y no con una persona consciente como en el conjunto de analogías anteriormente criticado. La planta-persona como tal, podría asumirse "inconsciente", pues al denominársele de este modo se podría interpretar como una semilla-embrión con la potencialidad de ser planta-persona. Sin embargo, como ya se anotó, en esta analogía el cuerpo de la mujer es siempre comparado por la autora con una casa, a la cual se le pueden colocar unas mallas en las ventanas para protegerla del polen que flota en el aire y dicha comparación del cuerpo de la mujer con un objeto separado de su conciencia, ya ha sido expuesta, analizada y criticada.

La analogía del violinista puede considerarse la más fuerte al no omitir esta condición en la que se encontraría un feto y al no comparar el cuerpo de la mujer con un objeto exterior a ella. La premisa analógica de este razonamiento establece que "una mujer que lleve en su vientre un feto por causa de una violación es como una persona obligada a permanecer conectada al cuerpo de otra inconsciente para mantener la vida de esta". En la interpretación y depuración de esta premisa llegamos a establecer que una mujer que lleve en su vientre un hijo no deseado es como una persona obligada a permanecer conectada al cuerpo de otra inconsciente para mantenerla con vida. 
Sin embargo, habría que señalar que un famoso violinista inconsciente se encontraría en ese estado luego de haber sido consciente de su vida, de su talento musical, de su éxito, de la Sociedad de Amantes de la Música que lo protege y lo ayuda, de su propia capacidad para reconocer, componer e interpretar una partitura. También podría haber sido consciente de su enfermedad renal mortal aunque no se estuviera enterando de nada en el momento que lo conectaron a la persona obligada. Esta persona adulta, mayor y muy querida, como se nos presenta el violinista famoso, sería entonces un sujeto "inconsciente" luego de haber experimentado o haberse percatado de muchas realidades y sucesos del mundo que lo rodea.

No sucedería lo mismo con un feto. Aunque el estado en que se presenta el mencionado violinista, sería el mismo en que se encuentra un feto, el período de vivencias anterior a ese estado marca una diferencia importante para decidir si tanto el violinista como el feto tienen el mismo derecho a la vida. O si tanto al violinista como al feto se les está otorgando la misma oportunidad en relación con el derecho a la vida. La diferencia general que presentan los casos expuestos por la autora con el caso de un embarazo, consistiría precisamente en que el hecho de tener que mantener o no la vida de otra persona no es tan semejante proporcionalmente a tener que dar o no la oportunidad de la vida a otra persona. En otros términos, la mujer está causalmente ligada a la posibilidad del feto, mientras que en el caso del violinista esto no se da. La causalidad, categoría filosófica que denota la conexión necesaria de los fenómenos, considera que entre estos, uno de los dos (denominado causa) condiciona a otro (denominado efecto). Las conexiones causales poseen un carácter multiforme y no es posible reducirlas a un solo tipo. De este modo, ante muchas otras circunstancias que existen ya en la situación de un embarazo y que forman las condiciones para que la causa actúe, se produce el efecto del feto. Por esta razón, podemos afirmar que la mujer es causa parcial fundamental del feto. El feto surge como materia del mismo cuerpo de la madre, como efecto de esa causa específica. En un tipo de decisión que involucra el deber de otorgar la vida y no el deber de mantener con vida a otra persona, luego de haber vivido una gran parte de esta, resulta moralmente relevante tal relación causal entre la madre y el feto.

La conciencia moral se halla estrechamente vinculada al deber, y el deber cumplido, como activa reacción del ser humano en respuesta a las exigencias de la sociedad y de su propia persona, constituye una poderosa fuerza interna de su accionar y de su perfeccionamiento ético.

El feto es, como efecto, materia reducida en extensión, posibilidades y sobre todo en cualidades morales, en relación con la madre, causa fundamental material o cuerpo "mayor".

La mujer, como causa específica y eficiente del feto, se enfrenta a una de las exigencias morales más peculiares que una persona pueda experimentar. Esta exigencia moral representa una profunda reflexión acerca de la responsabilidad no solo causal, sino también acerca de la responsabilidad efectista de llevar a cabo o no tal acción. Al tener que decidir una mujer como causa, si permanece o no conectada al feto como efecto de su propio cuerpo y de su propia decisión, experimenta una de las responsabilidades más particulares que experimentaría alguien en relación con cualquier otra persona, aunque esa persona sea o no "un famoso violinista inconsciente".

La observación o auto-observación de los fenómenos físicos externos y psíquicos internos, propios del embarazo, resultan en el caso del aborto, una experiencia personal moralmente peculiar. El hecho de que el origen y desarrollo de una persona se halle unido a las posibilidades físicas, al deseo, consentimiento y aprobación de otra persona como forma superior a esta, como su causa parcial específica, adquiere connotaciones moralmente muy 
distintas a las que presenta muy elocuentemente Judith Jarvis Thomson al lector en su original analogía del violinista famoso.

En la toma de cualquier decisión en nuestras vidas, se presenta una inevitable angustia existencial diríamos sartrianamente. Si estamos condenados a ser libres por nuestra posibilidad de elegir siempre entre esto o lo otro, en el caso de un posible aborto, la angustia se torna aún mayor. La mujer, al comprender y experimentar que a su cuerpo, que ciertamente le pertenece, se le ha sumado una inesperada parte que depende causal y directamente de ella para llegar a ser, se enfrenta a una de las elecciones o decisiones más complejas a las que se pueda enfrentar cualquier otra persona en circunstancias distintas, como las expuestas por la autora en sus analogías.

La situación de estar conectado sanguíneamente a otra persona adulta exterior a mí, no representa lo mismo que estar en estado de embarazo y ligada intra-uterinamente al inicio y desarrollo de la vida de un feto. El feto se concibe, gesta y desarrolla dentro de un órgano naturalmente acondicionado y que es parte del cuerpo de la futura madre.

En relación con el tiempo que tendría que permanecer conectada la persona obligada a mantener la vida del violinista, comparado con el tiempo que tendría que pasar una mujer en estado de embarazo conectada al feto, podríamos objetarle a Thomson que, en general, los embarazos no obligan a todas las mujeres a permanecer en cama durante los nueve meses. La persona se puede movilizar y realizar actividades diarias, a menos que presente dificultades, riesgos de aborto espontáneo u otros problemas más serios de salud. En este sentido, una mujer embarazada y un feto no serían como una persona obligada a permanecer conectada al sistema circulatorio de otra. Aunque la analogía ilustra bien en determinados aspectos la semejanza de ese suceso del violinista con el caso de un embarazo, el contacto o relación que se establece entre una mujer embarazada y el feto es muy distinta al expuesto.

Thomson podría sugerir que dentro de su analogía el canal o conducto que establece la conexión es suficientemente largo como para que la otra persona se pueda movilizar. Entonces habría que aclarar cómo el hecho de realizar una simple desconexión puede ser comparado con el hecho de realizar un aborto. Y esto sí puede resultar moralmente significativo. La misma autora nos dice al respecto que:

\footnotetext{
Si hay algo en el mundo que sea cierto es que si usted extiende la mano y se desconecta del violinista para salvar su vida, usted no está cometiendo un asesinato, no está haciendo nada no permisible (Thomson 1992: 15).
}

Como se ve, la desconexión del violinista la haría la misma persona que no quiere sacrificar ese tiempo de su vida, ni sus proyectos inmediatos o a largo plazo, por ayudarle y mantenerlo con vida. Sin embargo, ninguna mujer puede practicarse a sí misma un aborto de una manera tan simple o sin que corra realmente peligro su vida.

Aunque Thomson admite (1992: 11) que esto da un matiz diferente a la situación, considera que la diferencia no es decisiva, porque si la mujer es la dueña de su cuerpo (de su útero), como la persona conectada al violinista es la dueña de sus riñones, esta tendría derecho a su uso sin obstáculos y las demás personas tendrían que intervenir a favor de la mujer embarazada que decida abortar, sobre todo en el caso de que se vea amenazada su vida.

Sin embargo, una "desconexión” y un aborto presentan características fundamentales técnicamente distintas. Aunque la "desconexión" de una mujer y un feto pueda verse como un "corte" del cordón umbilical que los une, habría que considerar también que en caso de un aborto, al zigoto o al feto en sus primeros días de concepción, habría que aniquilarlo, partirlo, 
o aplicarle alguna solución salina para hacerlo "desalojar". Thomson deja claro en su analogía que "desconectarse" del violinista "significaría matarlo", porque "sólo usted tiene el grupo sanguíneo adecuado para ayudarle”, pero aún así, aparte de cualquier consideración ética, son dos tipos de muerte técnicamente distintos.

Por otra parte, en relación con esta analogía del violinista y la de Henry Fonda, la autora nos dice que no tenemos "ese tipo especial de responsabilidad" por la vida o bienestar de otra persona "si no la hemos asumido explícita o implícitamente". Por esta razón, no se le podría exigir a Henry Fonda que acceda a venir, o a la persona obligada a que permanezca conectada al violinista.

Luego de lo que hemos expuesto en relación con la importancia de la responsabilidad que determina una relación distinta entre la mujer y el feto, y la relación entre la persona obligada y el violinista, esta afirmación de la autora nos lleva a cuestionar no a Henry Fonda si no viniera, ni a la persona obligada si no accediera a permanecer conectada, sino a la posible o evidente diferencia que se da entre una responsabilidad como esta en esos casos y otra responsabilidad en el caso de un embarazo. Es decir, la responsabilidad que tendría o no que asumir la "persona obligada" o "Henry Fonda" y la que tendría que asumir una mujer en relación con su embarazo y con su hijo, son responsabilidades distintas.

La autora ha hecho ver dentro de su argumentación que un embarazo y llegar a ser madre "exige grandes sacrificios" y que la persona "enferma de muerte", en este caso analogada con el feto, no tendría derecho a exigir esos grandes sacrificios. Sin embargo, es precisamente la desproporción que se establece entre una "persona obligada" o "Henry Fonda" y una mujer embarazada en estas analogías, la que marca la diferencia entre una "responsabilidad especial" y otras menos comunes y corrientes como las expuestas por la autora en sus experimentos mentales.

Aunque no ocurra muy a menudo que alguien requiera de una "mano fría" para salvar su vida, Henry Fonda o cualquier otra persona, podría trasladarse, con grandes sacrificios, y posar esa mano fría sobre la frente febril de la persona "enferma de muerte" y luego marcharse tranquilamente sin ninguna otra preocupación o responsabilidad en el asunto de esa otra persona. Pero, la mujer que por decisión, azar o imposición queda embarazada y llega a ser madre, enfrenta una de las funciones humanas más recargadas de demanda y responsabilidad. Una mujer contribuye con todo su ser al hijo que nace y lo cría con su historia, su experiencia y su vida cotidiana de alegrías, dolores, satisfacciones, sufrimientos, temores, y en muchísimos casos, sobre todo en nuestros países pobres, lo cría con grandes limitaciones económicas. Si tomamos en cuenta no solo la relación entre el derecho a la vida y el derecho a disponer del cuerpo que tienen las personas, que es lo que ha interesado mayormente a la autora, sino también el derecho a vivir de la mejor manera posible, podríamos afirmar que solo una mujer que se valore a sí misma, que tenga las condiciones materiales y sociales necesarias para esto y entienda lo que traer un hijo(a) al mundo significará para ella y para esa otra persona, podrá luchar por su propia realización antes de asumir la responsabilidad de ser madre. De manera que pueda luego formar hijos que respeten a sus semejantes, que se realicen como persona integral y que desde la cuna puedan convivir con la confianza y el derecho a la felicidad. Es precisamente la concientización de esta especial responsabilidad la que hará que una mujer valore en su justa medida la decisión de interrumpir o no su embarazo. Por esta razón, el hecho de que no tengamos "ese tipo especial de responsabilidad" con nadie, en los casos que nos presenta con gran retórica la autora, marcan justamente la diferencia fundamental entre ese tipo de 
responsabilidad y la especial responsabilidad que implicaría llegar a ser madre. Es tal vez por esta vía, por la que se pueda lograr mayormente que se permita el aborto en embarazos

no deseados y que se acepte el aborto psico-social en aquellos embarazos y nacimientos de personas que no van a ser bien asumidos.

\section{Bibliografía}

Casas, Manuel Gonzalo. 1962. Sciacca. Buenos Aires: Editorial Columba.

Churchland, Patricia. 1986. Neuro- philosophy: toward unified science of mind and brain. Cambridge, Massachusetts: MIT Press.

1992. A neuro- computational perspective: the nature of mind and the structure of science. Massachusetts: MIT Press.

Copi, lrwing. 1973. Lógica Simbólica. México: Editorial Continental.

1984. Introducción a la Lógica. Buenos Aires: Editorial Universitaria.

Delfina, Ricardo. 1964. Cuerpo y Alma en Merleau Ponty. Buenos Aires: Editorial San Martín.

Ferrater Mora, José. 1958. Diccionario de Filosofía. Buenos Aires: Editorial Sudamericana

Marcel, Gabriel. 1956 Diario Metafísico. Buenos Aires: Editorial Losada.

1964. El misterio del Ser. Buenos Aires: Editorial Suramericana.

Merleau- Ponty, Maurice.1945. Phenoménologie de la Perception. París: Gallimard.

Rosental, M. y P. Ludin. 1973. Diccionario Filosófico. Argentina: Ediciones Universo.

Sartre, Jean Paul. 1960. L'etre et le néant, essai d'ontoloqie Phenomenoloqique. París: Gallimard.

Sciacca, Michelle Federico. 1958. El hombre este desequilibrado. Barcelona: Editorial Miracle.

Soto Badilla, José Alberto. 1976. "Paideia Latinoamericana y Filosofía de la integralidad". Folia Humanística. 14: 161- 165.

Thomson, Judith. 1971. A Defense of Abortion. Princeton: University Press.

1977. Acts and Other Events. Corneill: University Press. 
1992. Una Defensa del Aborto. Madrid: Ediciones Cátedra S.A.

1990. The Realm of Rights. Harvard: University Press.

Thomson, Judith y William Parent. 1986. Rights, Restitution and Risk: Essays in Moral Theory. Harvard: University Press.

Thomson, Judith y Gilbert Harman. 1996. Moral Relativism and Moral Objectivity. Blackwell Press.

Toulat, Jean. 1975. El aborto ¿crimen o liberación? Bilbao: Editorial Mensajero.

Tubert, Silvia. 1996. Figuras de la Madre. Madrid: Editorial Cátedra.

Walter, Ingo F. 1993. Van Gogh. Alemania: Editorial Taschen. 
